\title{
Clinical utility gene card for: Progressive familial intrahepatic cholestasis type 3
}

\author{
Emmanuel Gonzales ${ }^{1,2}$, Anne Spraul ${ }^{3}$ and Emmanuel Jacquemin ${ }^{\star, 1,2}$ \\ European Journal of Human Genetics (2014) 22, doi:10.1038/ejhg.2013.188; published online 4 September 2013
}

\section{DISEASE CHARACTERISTICS}

1.1 Name of the disease (synonyms)

1. Progressive familial intrahepatic cholestasis type 3 (PFIC3).

2. Multidrug resistance 3 (MDR3) deficiency.

PFIC3 is a hereditary disorder in bile formation because of a defect of MDR3, which is hepatocellular in origin., ${ }^{1,2}$

\subsection{OMIM\# of the disease}

602347.

1.3 Name of the analysed genes or DNA/chromosome segments ATP-binding cassette sub-family $\mathrm{B}$, member 4 or $A B C B 4$.

Chromosome 7q21.1 (g.87105019-87031362).

\subsection{OMIM\# of the gene(s)}

171060.

\subsection{Mutational spectrum}

Disease-causing mutations are mostly point mutations (80\%; missense, nonsense and splicing) spread all over the 27 coding exons but also small deletions, insertions and duplications (10-20\%) are reported. $^{2-4}$

Mutations of $A B C B 4$ can be found in the NHLBI ESP Exome Variant Server database (http://evs.gs.washington.edu/EVS/).

\subsection{Analytical methods}

Bidirectional $A B C B 4$ gene sequencing of all coding exons and short adjacent intronic sequences (RefSeq accession number: Refseq NM_000443).

When the analysis fails to identify both mutant alleles, a search for (partial) gene deletion or duplication by qPCR, microarray typing and multiplex ligation-dependant probe identification may be considered. ${ }^{5}$

\subsection{Analytical validation}

Independent sequencing of both strands of DNA (forward and reverse).

Quality control through sharing sample may be considered.

When heterozygosity for two mutations is found, testing of the patient's parents is recommended, to confirm that the defect is biallelic.
In case of novel intronic, silent or missense identified variation, a polymorphism has to be excluded by testing a set of at least 100 control chromosomes of the same ethnic origin. Pathogenicity of such novel variations has to be tested by in silico prediction methods. Concerning splice site variants, their pathogenic nature should be studied by cDNA analysis (RT-PCR and sequencing). Moreover, protein stability and trafficking may be studied in cell lines on a research basis.

\subsection{Estimated frequency of the disease}

(Incidence at birth ('birth prevalence') or population prevalence. If known to be variable between ethnic groups, please report):

The population prevalence of PFIC3 is unknown.

However, it is estimated around 1/100 000 births.

\subsection{Diagnostic setting}

\begin{tabular}{lll}
\hline & Yes & No \\
A. (Differential) diagnostics & $\Downarrow$ & $\square$ \\
B. Predictive testing & $\square$ & $\square$ \\
C. Risk assessment in relatives & $\bigotimes$ & $\square$ \\
D. Prenatal & $\Downarrow$ & $\square$ \\
\hline
\end{tabular}

Comment:

PFIC3 is a hereditary disorder in bile formation because of a defect of MDR3 involved in biliary phospholipid excretion. Transmission is autosomal recessive. PFIC3 should be suspected in children, or adolescents, or young adults with a clinical history of cholestasis of unknown origin after exclusion of other main causes of cholestasis. ${ }^{2}$ Patients present with high serum $\gamma$-GT activity, normal cholesterol level and moderately raised bile acid concentration. Liver ultrasonography is usually normal but may reveal a huge gallbladder and sometimes biliary stones. Liver histology reveals portal fibrosis and true ductular proliferation with mixed inflammatory infiltrate and, at a later stage, signs of biliary cirrhosis. MDR3 immunostaining may help for diagnosis. Cholangiography generally shows a normal biliary tree, unlike usual sclerosing cholangitis. Bile collection allows biliary lipid analysis showing decreased biliary phospholipid level.

Differential diagnosis includes biliary tract diseases, causes of intrahepatic cholestasis and of cirrhosis with elevated $\gamma$-GT. 
Monoallelic mutation of $A B C B 4$, predisposes to drug-induced cholestasis (DIC), intrahepatic cholestasis of pregnancy type 3 (ICP3, OMIM 147480), low phospholipid-associated cholelithiasis (LPAC, OMIM 600803), transient neonatal cholestasis (TNC) and fibrosing cholestatic liver disease in adults. ${ }^{6-10}$ Specialised medical follow-up and specific treatment with AUDC should be discussed in heterozygous relatives.

\section{TEST CHARACTERISTICS}

\begin{tabular}{|c|c|c|c|c|}
\hline & \multicolumn{2}{|c|}{ Genotype or disease } & \multirow{2}{*}{$\begin{array}{l}\text { A: True positives } \\
\text { B: False positives }\end{array}$} & \multirow{2}{*}{$\begin{array}{l}\text { C: False negative } \\
\text { D: True negative }\end{array}$} \\
\hline & Present & Absent & & \\
\hline \multicolumn{5}{|l|}{ Test } \\
\hline \multirow[t]{2}{*}{ Positive } & $A$ & B & Sensitivity: & $A /(A+C)$ \\
\hline & & & Specificity: & $D /(D+B)$ \\
\hline \multirow[t]{2}{*}{ Negative } & C & D & Positive predictive value: & $A /(A+B)$ \\
\hline & & & Negative predictive value: & $\mathrm{D} /(\mathrm{C}+\mathrm{D})$ \\
\hline
\end{tabular}

\subsection{Analytical sensitivity \\ (proportion of positive tests if the genotype is present) \\ Approximately 100\%.}

\subsection{Analytical specificity}

(proportion of negative tests if the genotype is not present)

Approximately $100 \%$.

\subsection{Clinical sensitivity}

\section{(proportion of positive tests if the disease is present)}

The clinical sensitivity can be dependent on variable factors such as age or family history. In such cases, a general statement should be given, even if a quantification can only be made case by case.

Approximately $90 \%$.

In few patients with a PFIC3 phenotype (including low biliary phospholipids levels or faint MDR3 immunostaining on liver biopsy), only one disease-causing mutation has been identified. ${ }^{2-4}$

\subsection{Clinical specificity}

(proportion of negative tests if the disease is not present)

The clinical specificity can be dependent on variable factors such as age or family history. In such cases a general statement should be given, even if a quantification can only be made case by case.

Approximately 100\%.

\subsection{Positive clinical predictive value}

(life-time risk to develop the disease if the test is positive)

There is no case report of an asymptomatic person harbouring two predictedly pathogenic mutations in biallelic state. In case of known disease-causing mutations, virtually $100 \%$ of affected individuals develop cholestasis. PFIC3 constitutes the severe side of the clinical spectrum of MDR3 deficiency. However, patients asymptomatic until adulthood despite compound heterozygosity for $A B C B 4$ defects are reported. ${ }^{11}$

2.6 Negative clinical predictive value (probability not to develop the disease if the test is negative) Assume an increased risk based on family history for a non-affected person. Allelic and locus heterogeneity may need to be considered.
Index case in that family had been tested:

Practically $100 \%$.

Index case in that family had not been tested:

Practically $100 \%$.

\section{CLINICAL UTILITY}

3.1 (Differential) diagnostics: the tested person is clinically affected (To be answered if in 1.9 'A' was marked)

\subsubsection{Can a diagnosis be made other than through a genetic test?}

\begin{tabular}{lll}
\hline No & (Continue with 3.1.4) & \\
Yes & $X$ & $\square$ \\
& Clinically & $\square$ \\
& Imaging & $\square$ \\
& Endoscopy & $\square$ \\
& Biochemistry & $\square$ \\
& Electrophysiology & $\square$ \\
& Other (please describe): & See below
\end{tabular}

3.1.2 Describe the burden of alternative diagnostic methods to the patient

A combined clinical, biochemical, radiological and histological approach associated with liver immunostaining and biliary lipid analysis can allow a PFIC3 diagnosis. However, to use genetic study to confirm clinicopathologic diagnoses - made through study of clinical, biochemical, imaging-study, and histopathologic findings, with immunostaining and ultrastructural evaluation - is generally prudent. $^{12}$

3.1.3 How is the cost effectiveness of alternative diagnostic methods to be judged?

Unknown.

3.1.4 Will disease management be influenced by the result of a genetic test?

$\begin{array}{ll}\text { No } & \square \\ \text { Yes } & \bigotimes \\ & \text { Therapy (please describe) } \\ & \text { Prognosis (please describe) } \\ & \text { Management (please describe) }\end{array}$

Ursodeoxycholic acid therapy (UDCA) should be initiated in all patients to prevent liver damage but is not fully efficient. ${ }^{12,13}$ Rifampicin is helpful to control pruritus. Recently, treatment with ciclosporin A was shown to partially correct, in vitro, the aberrant folding caused by one missense mutation. ${ }^{14}$ In the future, cell, gene or targeted mutation-specific pharmacological therapies might be useful tools for the management of patients with all types of PFIC. ${ }^{15}$

A beneficial effect of UDCA is usually observed in patients who harbour at least one missense variation (unlike in children with biallelic mutations that both lead to the synthesis of a truncated protein). ${ }^{2,12}$ In half of PFIC3 patients, UDCA therapy fails and liver transplantation is required before adulthood because of liver failure. In addition to the natural history and complications of PFIC3 (portal hypertension, liver failure, cirrhosis, etc.), children with ABCB4 mutations not evident clinically in childhood are theoretically at risk, later in life, of developing biliary stones, DIC and ICP $3 .{ }^{11}$ Girls receiving UDCA for MDR3 deficiency who reach adulthood with 
their native liver must not stop UDCA during pregnancy because the risk is substantial of precipitating more severe cholestasis thereby.

Life-long specialised medical follow-up is mandatory.

3.2 Predictive setting: the tested person is clinically unaffected but carries an increased risk based on family history

(To be answered if in 1.9 'B' was marked)

\subsubsection{Will the result of a genetic test influence lifestyle and prevention?}

If the test result is positive (please describe).

If the test result is negative (please describe).

\subsubsection{Which options in view of lifestyle and prevention does a person} at-risk have if no genetic test has been done (please describe)?

Not applicable.

3.3 Genetic risk assessment in family members of a diseased person (To be answered if in $1.9^{~ '} \mathrm{C}$ ' was marked)

\subsubsection{Does the result of a genetic test resolve the genetic situation in} that family?

If the two disease-causing mutations have been identified in the diseased person, family members with a negative test are not at risk for being affected. However, a heterozygous status predisposes to DIC, ICP3, TNC, LPAC and adult biliary fibrosis.

3.3.2 Can a genetic test in the index patient save genetic or other tests in family members?

Yes. In case of a known familial mutation, carriership can be confirmed or excluded.

3.3.3 Does a positive genetic test result in the index patient enable a predictive test in a family member?

As MDR3 deficiency at a heterozygous status predisposes to develop ICP3, DIC, TNC and also LPAC a predictive test can be offered to family members.

In asymptomatic relatives with monoallelic mutation, information regarding the particular risks should be given. Specialised medical care (including UDCA treatment) and follow-up should be offered to symptomatic relatives with monoallelic mutation.

\subsection{Prenatal diagnosis}

(To be answered if in 1.9 'D' was marked)

\subsubsection{Does a positive genetic test result in the index patient enable a prenatal diagnosis?}

Prenatal diagnosis can be proposed if a mutation has been identified in each parent.

\section{IF APPLICABLE, FURTHER CONSEQUENCES OF TESTING}

Please assume that the result of a genetic test has no immediate medical consequences. Is there any evidence that a genetic test is nevertheless useful for the patient or his/her relatives? (please describe)

Genetic counselling is always useful for the family.

\section{CONFLICT OF INTEREST}

The authors declare no conflict of interest.

\section{ACKNOWLEDGEMENTS}

This work was supported by EuroGentest2 (Unit 2: 'Genetic testing as part of health care'), a Coordination Action under FP7 (Grant Agreement Number 261469) and the European Society of Human Genetics.

1 De Vree JML, Jacquemin E, Sturm E et al: Mutations in the MDR3 gene cause progressive familial intrahepatic cholestasis. Proc Natl Acad Sci USA 1998; 95: 282-287.

2 Jacquemin E, de Vree JLM, Cresteil D et al: The wide spectrum of multidrug resistance 3 deficiency: from neonatal cholestasis to cirrhosis of adulthood. Gastroenterology 2001: 120: 1448-1458.

3 Degiorgio D, Colombo C, Seia $\mathrm{M}$ et al: Molecular characterization and structural implications of 25 new ABCB4 mutations in progressive familial intrahepatic cholestasis type 3 (PFIC3). Eur J Hum Genet 2007; 15: 1230-1238.

4 Colombo C, Vajro P, Degiorgio D et al: Clinical features and genotype-phenotype correlations in children with progressive familial intrahepatic cholestasis type 3 related to ABCB4 mutations. J Pediatr Gastroenterol Nutr 2011; 52: 73-83.

5 Pasmant $E$, Goussard P, Baranes L et al: First description of ABCB4 gene deletions in familial low phospholipid-associated cholelithiasis and oral contraceptives-induced cholestasis. Eur J Hum Genet 2012; 2: 277-282.

6 Pauli-Magnus $\mathrm{C}$, Lang $\mathrm{T}$, Meier $\mathrm{Y}$ et al: Sequence analysis of bile salt export pump (ABCB11) and multidrug resistance p-glycoprotein 3 (ABCB4, MDR3) in patients with intrahepatic cholestasis of pregnancy. Pharmacogenetics 2004; 14: 91-102.

7 Rosmorduc 0, Hermelin B, Poupon R: MDR3 gene defect in adults with symptomatic intrahepatic and gallbladder cholesterol cholelithiasis. Gastroenterology 2001; 120: 1459-1467.

8 Jacquemin E, Lykavieris $\mathrm{P}$, Chaoui $\mathrm{N}$ et al: Transient neonatal cholestasis: origin and outcome. J Pediatr 1998; 133: 563-567.

9 Lucena JF, Herrero JI, Quiroga J et al: A multidrug resistance 3 gene mutation causing cholelithiasis, cholestasis of pregnancy, and adulthood biliary cirrhosis. Gastroenterology 2003; 124: 1037-1042.

10 Ziol M, Barbu V, Rosmorduc 0 et al: ABCB4 heterozygous gene mutations associated with fibrosing cholestatic liver disease in adults. Gastroenterology 2008; 135: 31-41

11 Ganne-Carrié N, Baussan C, Grando V et al: Progressive familial intrahepatic cholestasis type 3 revealed by oral contraceptive pills. J Hepatol 2003; 38 : 693-694.

12 Davit-Spraul A, Gonzales E, Baussan C et al: The spectrum of liver diseases related to ABCB4 gene mutations: pathophysiology and clinical aspects. Semin Liver Dis 2010; 30: $134-146$.

13 Jacquemin E, Hermans D, Myara A et al: Ursodeoycholic acid therapy in pediatric patients with progressive familial intrahepatic cholestasis. Hepatology 1997; 25: 519-523.

14 Gautherot J, Durand-Schneider AM, Delautier D et al: Effects of cellular, chemical, and pharmacological chaperones on the rescue of a trafficking-defective mutant of the ATP-binding cassette transporter proteins ABCB1/ABCB4. J Biol Chem 2012; 287: 5070-5078.

15 Gonzales E, Jacquemin E: Mutation specific drug therapy for progressive familial or benign recurrent intrahepatic cholestasis: a new tool in a near future? J Hepatol 2010; 53: 385-387. 